This document is the Accepted Manuscript version of a Published Work that appeared in final form in ACS Appl. Mater. Interfaces, copyright $\odot$ American Chemical Society after peer review and technical editing by the publisher. To access the final edited and published work see [insert ACS Articles on Request author-directed link to

\title{
Thermally Responsive Capillary Suspensions
}

\author{
Anupam A. K. Das, ${ }^{\dagger}$ Timothy S. Dunstan, ${ }^{\dagger}$ Simeon D. Stoyanov, ${ }^{\ddagger}, \|_{\odot \odot}$ Pierre Starck, ${ }^{\perp}$ \\ and Vesselin N. Paunov* ${ }^{*}+$ (1) \\ ${ }^{\dagger}$ School of Mathematics and Physical Sciences (Chemistry), University of Hull, Hull HU6 7RX, U.K. \\ "Unilever R\&D Vlaardingen, Olivier van Noortlaan 120, Vlaardingen 3133 AT, The Netherlands \\ ${ }^{\S}$ Laboratory of Physical Chemistry and Soft Matter, Wageningen University, Wageningen $6703 \mathrm{HB}$, The Netherlands \\ "Department of Mechanical Engineering, University College London, Torrington Place, London WC1E 7JE, U.K. \\ ${ }^{\perp}$ Unilever Discover Port Sunlight, Quarry Road East, Bebington CH63 3JW, U.K.
}

\section{Supporting Information}
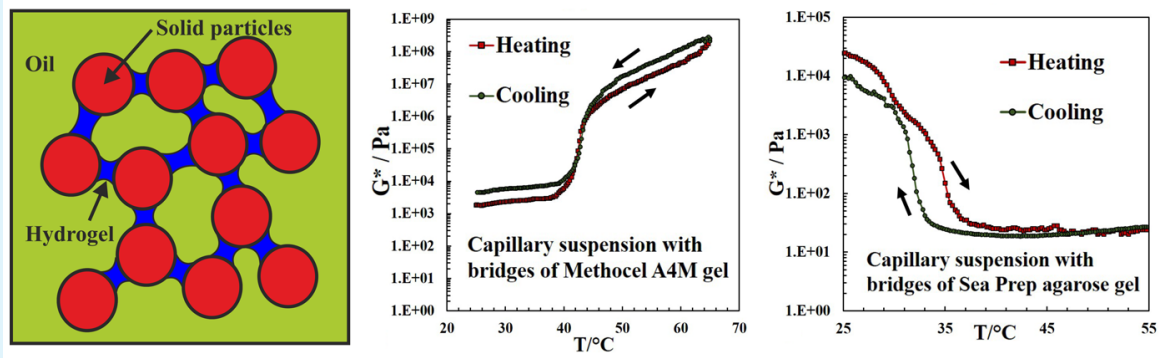

ABSTRACT: We demonstrate that stimulus-responsive capillary-structured materials can be formed from hydrophobized calcium carbonate particles suspended in a non-polar phase (silicone oil) and bridged by very small amounts of a hydrogel as the secondary aqueous phase. Inclusion of thermally responsive polymers into the aqueous phase yielded a capillary-structured suspension whose rheology is controlled by a change in temperature and can increase its complex modulus by several orders of magnitude because of the gelation of the capillary bridges between the solid particles. We demonstrate that the rheology of the capillary suspension and its response upon temperature changes can be controlled by the gelling properties as little as $0.1 \mathrm{w} / \mathrm{w} \%$ of the secondary aqueous phase containing $2 \mathrm{wt} \%$ of the gelling carbohydrate. Doping the secondary (aqueous) phase with methyl cellulose, which gels at elevated temperatures, gave capillary-structured materials whose viscosity and structural strength can increase by several orders of magnitude as the temperature is increased past the gelling temperature of the methyl cellulose solution. Increasing the methyl cellulose concentration from 0 to $2 \mathrm{w} / \mathrm{w} \%$ in the secondary (aqueous) phase increases the complex modulus and the yield stress of the capillary suspension of $10 \mathrm{w} / \mathrm{w} \%$ hydrophobized calcium carbonate in silicone oil by 2 orders of magnitude at a fixed temperature. By using an aqueous solution of a low melting point agarose as a secondary liquid phase, which melts as the temperature is raised, we produced capillary-structured materials whose viscosity and structural strength can decrease by several orders of magnitude as the temperature is increased past the melting temperature of the agarose solution. The development of thermally responsive capillary suspensions can find potential applications in structuring of smart home and personal care products as well as in temperature-triggered change in rheology and release of flavors in foods and actives in pharmaceutical formulations.

KEYWORDS: capillary suspension, methyl cellulose, agarose, thermally responsive hydrogels, calcium carbonate, capillary structuring

\section{INTRODUCTION}

Capillary suspensions are formulations containing solid particles dispersed in a continuous liquid phase doped with minute amount of secondary liquid phase immiscible with the continuous phase. The addition of a very small amount of secondary phase can result in an increase of the yield stress of the suspension by several orders of magnitude. ${ }^{1}$ This change in the rheological properties of the suspension is induced by the capillary bridge forces occurring between the solid particles due to the secondary liquid phase, and they usually dominate all other interactions such as van der Waals, Brownian, electrostatic forces, steric, and hydrodynamic interactions. ${ }^{2-6}$ Over the past few years, the use of capillary bridge forces to make capillary suspensions with improved rheological properties has gained increased attention. ${ }^{7-10,22-24}$ The addition of the secondary fluid results in the formation of a sample spanning network, with major impact on the stability as well as the rheological properties of the capillary suspensions. ${ }^{11}$ It has also been found that the capillary suspensions are produced in two different ways; according to the wetting properties of the fluids

Received: July 31, 2017

Accepted: November 22, 2017 
to the particles. If the secondary liquid phase wets the particles better than the primary (continuous) phase, it forms capillary bridges in a pendular state, and if the continuous phase wets the solid particles better than the secondary one, this corresponds to a capillary state. ${ }^{12}$ In both cases, the secondary fluid forms an interconnected network of bridged particles. Depending on the wetting properties of the particles, both oil-based and waterbased capillary suspensions can be produced. Recently, Velankar proposed a non-equilibrium state diagram for liquid/fluid/particle mixtures. ${ }^{25}$

Koos and Willenbacher ${ }^{1}$ reported that the addition of the secondary fluid results in an increase in the viscosity of the suspension. Zhang et al. ${ }^{13}$ also showed that the further addition of the secondary fluid can significantly decrease the viscosity of the suspension. They also discussed the effect of addition of dispersant to the capillary suspension. These effects can be efficiently used to tune the rheological properties of the suspensions, resulting in the avoidance of using other additives such as binding agents and surfactants. Recently, Dunstan et al. $^{31}$ showed that hydrophilic calcium carbonate particles can form capillary suspensions when dispersed in water with very low concentration of secondary oil phase doped with oleic acid which in situ hydrophobizes the bridged particles surface. Capillary suspensions have already been used in various applications in the field of food sciences for making food products with less fat ${ }^{8}$ and control of texture and flow behavior in foods. ${ }^{21}$ They have also been used in the production of macroporous ceramic materials, ${ }^{7,14}$ porous glass filters, ${ }^{15,16}$ and slurries for the fabrication of Li-ion battery electrodes. ${ }^{17}$ Applications involving the preparation of highly conductive printable pastes ${ }^{20}$ and $3 \mathrm{D}$ printed porous polydimethylsiloxanebased capillary suspensions have recently been reported. ${ }^{26}$

The objective of this study is to take this approach further by making oil-based capillary-structured suspensions that are stimuli-responsive upon changing the external physical properties such as temperature. This would allow the fabrication of temperature-responsive capillary-structured formulations which have a significant effect on the respective rheological properties depending on the behavior of a gelling polymer present in the secondary fluid phase (see Scheme 1). Such formulations would respond to external stimuli such as change in temperature with changes in the respective rheological properties of the capillary bridges which hold the network structure of the capillary suspensions. The importance of this work comes from the possibility that such stimuli-responsive formulations can be used to produce various oil-based personal care products with the desired rheological properties tailored to the external environment.

We developed stimuli-responsive oil-based capillary suspensions by the addition of minute amount of different hydrogel solutions in water as the secondary liquid phase in a continuous oil phase containing the solid particles. This results in a sharp change in the capillary suspension rheology from a fluid-like material to a gel-like material. A change in external stimuli such as temperature resulted in extensive changes in the rheological properties of the formulations depending on the type of hydrogel-forming polymer used in the secondary liquid phase. The hypothesis is that aqueous solutions of low concentrations of certain polymers can be made in which the solution can be gelled or melted at set temperatures, causing a huge change in the viscosity of the capillary bridge-forming material. If this solution is incorporated into a capillary-structured material as the bridging aqueous phase between the particles suspended in
Scheme $1^{a}$

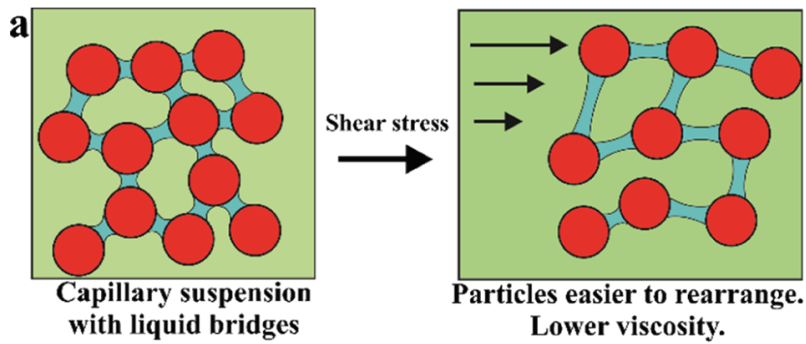

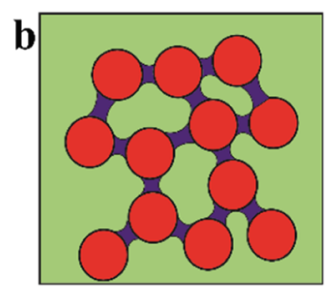

Capillary suspension with hydrogel bridges

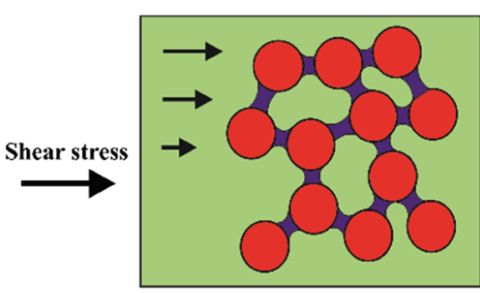

Gelled bridges resist rearranging. Higher viscosity.

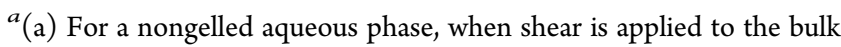
sample, the bridges can deform and stretch, allowing the bulk material to flow. (b) At temperatures where the aqueous phase of the capillary bridges is gelled, they resist deformation which inhibits the flow and increases the viscosity. Schematics of the response of the capillarystructured suspension in which the bridging (secondary) liquid phase can be gelled by changing the temperature.

a nonpolar medium, then it is expected that the rheological properties of the whole suspension will be governed by those of the bridging phase to a great extent; that is, a capillarystructured material whose bridges are formed of a flowable lowviscosity material might be expected to have significantly lower viscosity and yield stress than those of a capillary-structured material whose liquid bridges between the solid particles are gelled and resist stretching and rearrangement when the material is subjected to mechanical stress. Therefore, by changing the temperature to the melting point or gelling point of the bridging liquid phase, it should be possible to strongly influence the rheology of the capillary suspension.

We used two different hydrogel-forming polymers, methyl cellulose and agarose, to form a temperature-responsive bridging liquid phase in oil-based capillary suspensions. Methyl cellulose is a polymer consisting of backbone of linked glucose molecules with the native hydroxyl groups $(-\mathrm{OH})$ substituted by methoxyl groups $\left(-\mathrm{OCH}_{3}\right)$. Methyl cellulose is watersoluble at low temperatures where it forms a flowable liquid solution. However, upon heating up to the lower critical solution temperature, methyl cellulose precipitates out of solution and forms a hydrogel. The temperature at which this occurs is related to the degree of methylation of methyl cellulose, with greater substitution leading to a smaller lower critical solution temperature. ${ }^{18}$ The phase separation and gelation occur contemporaneously in an aqueous methyl cellulose solution with the change in temperature, resulting in the sol-gel transition at higher temperatures from a clear flowing solution in to a turbid hydrogel.

Agarose is a polymer of alternate D-galactose and 3,6anhydro-L-galactopyranose rings. Although insoluble in cold water, it hydrates and dissolves at high temperatures, forming a flowable aqueous solution which upon further cooling forms a 
strong hydrogel. At low temperatures, hydrogen bonding between the $\mathrm{D}$-galactose rings facilitates the formation of a network; these are disrupted upon heating, so the agarose hydrogel melts. ${ }^{19}$

In this study, we use aqueous solutions of these hydrogelforming polymers as the immiscible secondary liquid phase of a capillary suspension of pre-hydrophobized calcium carbonate particles (Socal 312) in silicone oil. This enabled us to control the rheological properties of this capillary-structured material by varying the temperature of the surroundings. This "smart" material would become thermally responsive because of the presence of methyl cellulose/agarose in the aqueous capillary bridges of the secondary phase between the solid particles whose gelation is expected to have a significant effect on the agglomeration and rearrangement of the solid particles upon change in temperature. The addition of the secondary hydrogel phase should induce the change from a fluidlike behavior to an elastic gel-like response at different temperatures. The rheology measurements were carried out by applying torsional stress on samples sandwiched between two surfaces.

The paper is organized as follows. The methods and materials are presented in the next section. We compare the rheology of oil-based capillary suspensions of ultrafine calcium carbonate particles in silicone oil structured by minute amounts of water with that of the same systems where, instead of water, aqueous solutions of agarose and methyl cellulose are used as a secondary liquid phase. We study their rheological response as a function of temperature and secondary phase concentration. We demonstrate that the rheology of the capillary suspension follows a trend similar to the rheology of the gelling aqueous phase in response to temperature.

\section{MATERIALS AND METHODS}

Materials. Silicone oil (silicone oil for oil baths -40 to $200{ }^{\circ} \mathrm{C}$, Alfa Aesar, purity not given), Methocel A4M (Dow, manufacturer-stated gelling temperature $60{ }^{\circ} \mathrm{C}$ ), SeaPrep agarose (Lonza, cat no. 50302, manufacturer-stated gel-melting temperature $\leq 30{ }^{\circ} \mathrm{C}$ ), and Socal 312 (Solvay) precipitated and hydrophobized $\mathrm{CaCO}_{3}$ particles were used as supplied; Dow Corning 200 Fluid $30000 \mathrm{cSt}$ and Dow Corning 200 Fluid $300 \mathrm{cSt}$ were also used as received. Deionized water was obtained from an ELGA Milli-Q unit.

Methods. Preparation of Methocel Aqueous Solution. A beaker was placed in an ice bath over a magnetic stirrer. Water was placed in the beaker with a stirrer bar and allowed to cool to $5{ }^{\circ} \mathrm{C}$. The desired amount of Methocel A4M was slowly added with continuous vigorous stirring. The beaker was covered and left stirring for $24 \mathrm{~h}$, with the temperature not exceeding $10^{\circ} \mathrm{C}$. After $24 \mathrm{~h}$, the solution was clear and flowed easily with no visible lumps of Methocel.

Preparation of SeaPrep Agarose Hydrogel. A beaker was placed in a water bath over a magnetic stirrer. Water was placed in the beaker with a stirrer bar and allowed to warm to $55{ }^{\circ} \mathrm{C}$. The desired amount of SeaPrep agarose was slowly added with continuous vigorous stirring. The beaker was covered and left stirring for $1 \mathrm{~h}$ at $55^{\circ} \mathrm{C}$. After $1 \mathrm{~h}$, the solution was placed in a fridge at $2{ }^{\circ} \mathrm{C}$ for $24 \mathrm{~h}$ and left to gel.

Formation of Oil-Based Capillary Suspensions. The silicone oil and the Socal 312 were added into a Tefal fruit sensation blender and mixed at power level 1 for $30 \mathrm{~s}$. An aliquot of the mixture was taken for analysis, the desired volume of aqueous phase was added by a pipette, and the system was reblended. This was repeated until the range of desired secondary phase concentrations had been achieved. All samples were placed in a desiccator under reduced pressure for $30 \mathrm{~s}$ immediately after formation.

Contact Angle Measurements. Contact angles of the Socal 312 particles at the interface between the continuous and the secondary liquid phases were determined by compressing the powder into a tablet using a $\mathrm{KBr}$ press. The tablet was placed in a cuvette on a Krüss
DSA 10 instrument and stuck down with a carbon scanning electron microscopy (SEM) mounting pad. The cuvette was filled with the silicone oil, and a $20 \mu \mathrm{L}$ drop of the aqueous phase was syringed onto the tablet surface and imaged with a Krüss DSA 10 digital camera.

Krüss DSA 10 software was used to measure the advancing contact angle through the water phase. The temperature was controlled by circulating water from a Grant LD50 thermostat around the water jacket built into the DSA 10 stage. A thermocouple was used to ensure that the temperature at the tablet surface was as desired. For the SeaPrep agarose solution at low temperatures, the syringe with the solution was prewarmed until the agarose gel melt which was followed by immediate formation of a drop in the silicone oil phase on the Socal 312 tablet surface at a fixed temperature. For the methyl cellulose solution, the syringe was filled with the solution at room temperature where the solution was liquid and then a drop was formed quickly in the silicone phase on the Socal 312 tablet surface at a fixed temperature.

Rheology Measurements. Rheology was determined using a Bohlin CVO-120 instrument fitted with $40 \mathrm{~mm}$ cones and plates. Unless stated otherwise, a Teflon-encased cone and plates were used in the rheometer. Controlled frequency stress sweep oscillatory measurements were made, at $1 \mathrm{~Hz}$. The stress sweep range was altered according to the viscosity of the material. The temperature was controlled to better than $\pm 0.1{ }^{\circ} \mathrm{C}$. The samples were allowed to thermally equilibrate for $10 \mathrm{~min}$ prior to the measurement. No preshear was used. A fresh sample was used for each measurement. The yield stress was determined by fitting curves with the equation $G^{*}$ $=a \sigma^{n}$ before and after the break point and calculating the intersection. Controlled temperature sweeps were made at a frequency of $1 \mathrm{~Hz}$ and controlled stresses of 1 and $5 \mathrm{~Pa}$. The sample was held at a low temperature for $10 \mathrm{~min}$ and then heated to the desired maximum temperature at a rate of $1{ }^{\circ} \mathrm{C} \mathrm{min}^{-1}$.

\section{RESULTS AND DISCUSSION}

For capillary-structured materials such as the one used in this study, where the particles are suspended in a nonpolar oil phase (silicone oil) and bridged by minute amounts of an aqueous phase, the nature of the surface of the rheometer plates is very important and should be carefully considered. For rheometer cones and plates made from hydrophilic materials such as stainless steel, the results obtained were not well-reproducible. To avoid this, we used Teflon-encased cones and plates in our rheometer. This enabled us to obtain reproducible data of multiple repeats of the different rheological experiments with oil-based capillary suspensions. More discussion on how to overcome these problems in the rheology measurement in the oil-based capillary suspensions is presented in the Supporting Information section (Figure S1).

We present the results of the rheological measurements of the samples made using Socal 312 particles dispersed in silicone oil with the added secondary phases of water, methyl cellulose, and agarose. All rheological measurements were carried out after the samples had been desiccated because of the fact that the presence of air can have a significant effect on the complex modulus of the system by forming a third fluid phase in certain conditions. $^{27}$ (Please refer to the Supporting Information for a more detailed study.)

Gelation and Melting of Aqueous Solutions of Methocel A4M (Methyl Cellulose) or SeaPrep (Agarose).

Figure 1 shows the variation in the complex modulus of solutions of Methocel A4M and SeaPrep in water with temperature. The methyl cellulose in water starts to show an increase in viscosity at $45{ }^{\circ} \mathrm{C}$, and it steadily increases with increasing temperature until a marked increase is observed at $60-65^{\circ} \mathrm{C}$. As evident from Figure 1, the agarose solution starts to decrease in viscosity at $30{ }^{\circ} \mathrm{C}$. It is expected from this that 


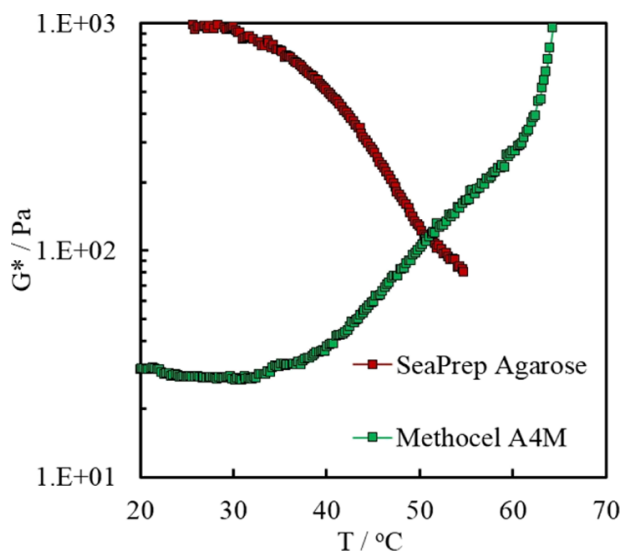

Figure 1. Complex modulus $\left(G^{*}\right)$ vs temperature $(T)$ for $2 \mathrm{w} / \mathrm{v} \%$ aqueous solution of Methocel $\mathrm{A} 4 \mathrm{M}$ and SeaPrep agarose. The measurements were done on a rheometer with Teflon-encased plates. The samples were measured at $1 \mathrm{~Hz}, 1 \mathrm{~Pa}$ applied stress, and a heating rate of $2{ }^{\circ} \mathrm{C} \mathrm{min}^{-1}$. SeaPrep agarose hydrogels have been shown to melt at temperatures exceeding $30{ }^{\circ} \mathrm{C}$.

for capillary suspensions including Methocel A4M in the secondary bridging phase, heating to $60{ }^{\circ} \mathrm{C}$ and above will result in significant changes in the rheology of the system. If SeaPrep agarose is used, then heating to temperatures above 30 ${ }^{\circ} \mathrm{C}$ will show observable changes in the rheology.

Rheology of the Capillary-Structured Suspensions with Pure Water as the Bridging (Secondary) Phase. Figure 2a shows the complex modulus as a function of applied

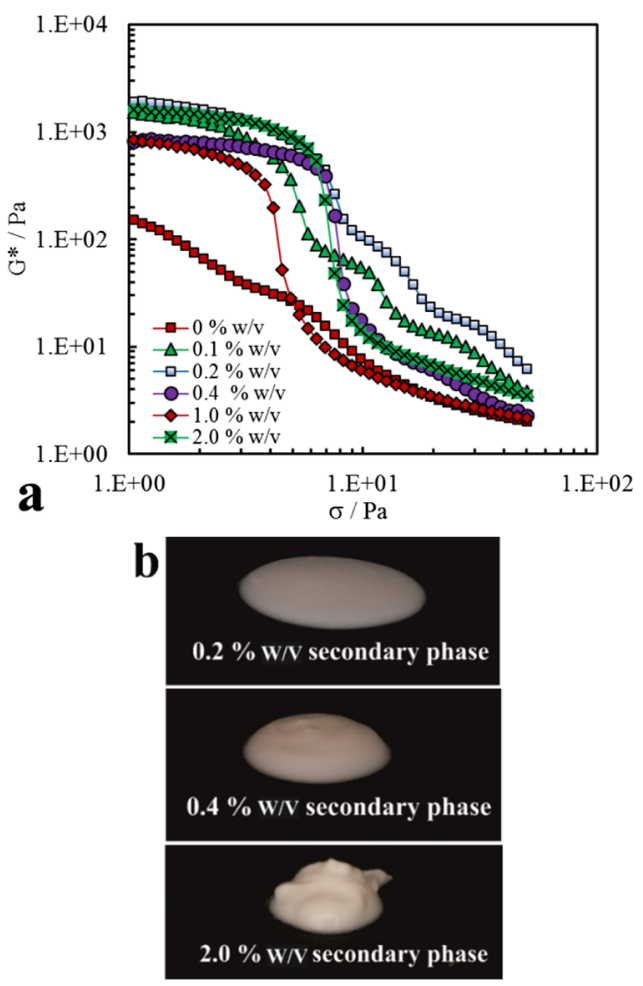

Figure 2. (a) Complex modulus $\left(G^{*}\right)$ as a function of shear stress $(\sigma)$ for a suspension of $10 \mathrm{w} / \mathrm{w} \%$ Socal 312 particles in silicone oil for varying concentrations of water as a secondary phase at $25^{\circ} \mathrm{C}$. The measurements were done on a rheometer with Teflon-encased plates. (b) Digital photographs of the capillary suspension at different concentrations of the secondary phase. stress for a series of capillary suspensions in which the primary phase is silicone oil, the particles are $10 \mathrm{w} / \mathrm{w} \%$ Socal 312, and the secondary phase is water, varying from 0 to $2 \mathrm{w} / \mathrm{v} \%$. The data in Figure 2a show the multiple steps in the $G^{*}$ versus stress amplitude curves, which indicate that these oil-based capillary suspensions exhibit complex structures depending on the content of the secondary aqueous phase.

It was found that the oil-based suspensions of particles with no added water have a relatively low complex modulus at a low shear stress and a low yield stress. The addition of minute amounts of water results in an increase of both the complex modulus and the yield stress significantly, in some cases, by 2 orders of magnitude. This result demonstrates that the addition of water results in the adherence of Socal 312 particles to each other in the oil, giving a structure to the suspension. Hence, this effect is attributed to the presence of water bridges linking the particles. ${ }^{14}$ This behavior was also visually demonstrated by the optical photographs of the samples shown in Figure $2 b$, where the low-complex modulus suspension with very little secondary phase flows compared to samples containing higher amounts of water. Increasing the amount of added water increases the number of liquid bridges, which, in turn, strongly increases the complex modulus and yields a capillary-structured material that can hold its shape. It was also observed that the multiple step change occurs only for samples containing less than $0.4 \%(\mathrm{w} / \mathrm{v})$ secondary phase, as evident from Figure $2 \mathrm{a}$. This phenomenon was not observed when the secondary phase of water was replaced with aqueous solutions of methyl cellulose and agarose. These are complex fluids, and a separate more detailed study has to be carried out to find the physics behind the multiple step changes in $G^{*}$ of the samples when water is used as a secondary phase.

The Socal 312 particles used in our system are ultrafine precipitated calcium carbonate with individual particle sizes ranging from 0.045 to $0.090 \mu \mathrm{m}$ (data supplied by Solvay Chemical Int) and $93 \pm 16 \mathrm{~nm}$ (data measured using dynamic light scattering), which makes it not feasible to observe individual liquid bridges formed between these submicrometer particles by using a fluorescence optical microscope. To reveal the type of liquid bridges in this system, we measured the values of the three-phase contact angle of aqueous drops under silicone oil on a tablet of compressed Socal 312 powder. The contact angle data indicate that the bridges of secondary phase formed are likely to be capillary, not pendular for this specific system from 25 to $65{ }^{\circ} \mathrm{C}$. The complex modulus of the system containing the secondary phase of water was measured at various temperatures $\left(25-65{ }^{\circ} \mathrm{C}\right)$. It was observed that the sample without a secondary liquid phase had no significant change in the complex modulus with temperature. However, for suspensions containing 0.2 and $1.0 \mathrm{w} / \mathrm{v} \%$ water as the secondary phase, there was a slight increase in the complex modulus as the temperature is increased, which is evident from Figure 3.

The complex modulus and the viscosity of the capillary suspension are dependent on the capillary bridge force acting between the bridged particles. The later, in turn, is dependent on the interfacial tension between the two liquid phases as well as the three-phase contact angle between the aqueous phase, the oil phase, and the particle surface. These are both temperature-dependent, so some complex temperature dependence of the viscosity of the capillary-structured materials is expected. The interfacial tension of the silicone oil-water interface decreases slightly with the increase in the temperature. 


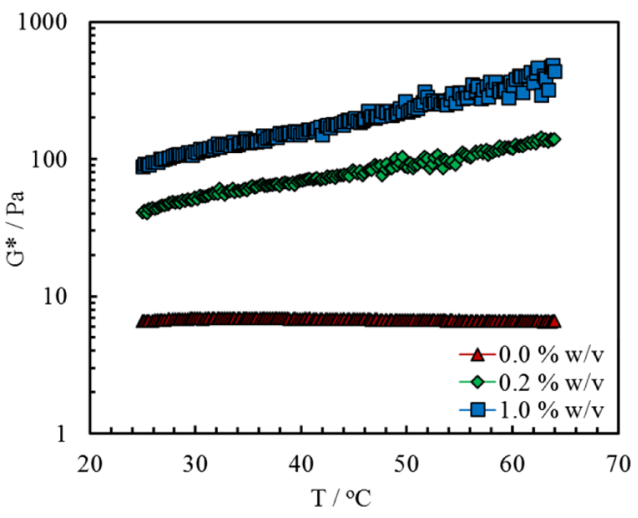

Figure 3. Complex modulus $\left(G^{*}\right)$ vs temperature $(T)$ for the $10 \mathrm{w} / \mathrm{w}$ $\%$ Socal 312 particle suspension in silicone oil for varying concentrations of the secondary liquid phase (water). The measurements were done on a rheometer at $1 \mathrm{~Hz}, 1 \mathrm{~Pa}$ applied stress, and a heating rate of $1{ }^{\circ} \mathrm{C} \mathrm{min}^{-1}$.

The effect of the contact angle dependence on the temperature plays in a direction opposite to that of the interfacial tension effect for the overall change in the complex modulus versus temperature. Because Figure 3 shows a slight increase in the complex modulus with the increase in the temperature, it is likely that the overall effect is governed by the increase in the capillary bridge force due to the change in the particle threephase contact angle and the interfacial tension, as shown in Table 1. The data also indicate that upon increasing the

Table 1. Advancing Three-Phase Contact Angles of a Drop of the Aqueous Secondary Phase on a Socal 312 Powder Tablet under Silicone $\mathrm{Oil}^{a}$

\begin{tabular}{|c|c|c|c|}
\hline temperature $/{ }^{\circ} \mathrm{C}$ & secondary phase & $\begin{array}{l}\mathrm{O} / \mathrm{W} \text { interfacial } \\
\text { tension } / \mathrm{mN} \mathrm{m}^{-1}\end{array}$ & contact angle/deg \\
\hline 25 & water & $38.1 \pm 0.5$ & $115 \pm 5$ \\
\hline 65 & water & $31.9 \pm 0.6$ & $91 \pm 4$ \\
\hline 25 & $\begin{array}{l}\text { methyl cellulose } \\
\text { aqueous solution }\end{array}$ & $37.4 \pm 0.4$ & $110 \pm 4$ \\
\hline 65 & $\begin{array}{l}\text { methyl cellulose } \\
\text { aqueous solution }\end{array}$ & $34.8 \pm 0.3$ & $93 \pm 4$ \\
\hline 25 & $\begin{array}{l}\text { SeaPrep agarose } \\
\text { aqueous solution }\end{array}$ & $36.2 \pm 0.4$ & $112 \pm 5$ \\
\hline 65 & $\begin{array}{l}\text { SeaPrep agarose } \\
\text { aqueous solution }\end{array}$ & $32.0 \pm 0.5$ & $89 \pm 4$ \\
\hline
\end{tabular}

${ }^{a}$ The methyl cellulose and SeaPrep agarose concentrations were both $2 \mathrm{w} / \mathrm{w} \%$ in the aqueous solutions.

temperature from 25 to $65{ }^{\circ} \mathrm{C}$, the liquid bridges of the secondary phase are changing from pendular towards a nearly capillary state. It is also likely that at higher temperatures, the lower silicone oil-water interfacial tension favors the dispersion of the aqueous phase to a larger number of drops which forms a larger number of liquid bridges between the particles.

Rheology of Socal 312 Particle Suspension in Silicone Oil with an Aqueous Solution of Methocel A4M as the Bridging Phase. The complex modulus of suspensions containing $10 \mathrm{w} / \mathrm{w} \%$ Socal 312 dispersed in the primary phase of silicone oil with different concentrations of aqueous solution of Methocel A4M (0-2 w/v \%) was measured as a function of applied stress. It was observed that the increase in the secondary phase of Methocel A4M results in a gradual increase in the complex modulus, as shown in Figure 4.

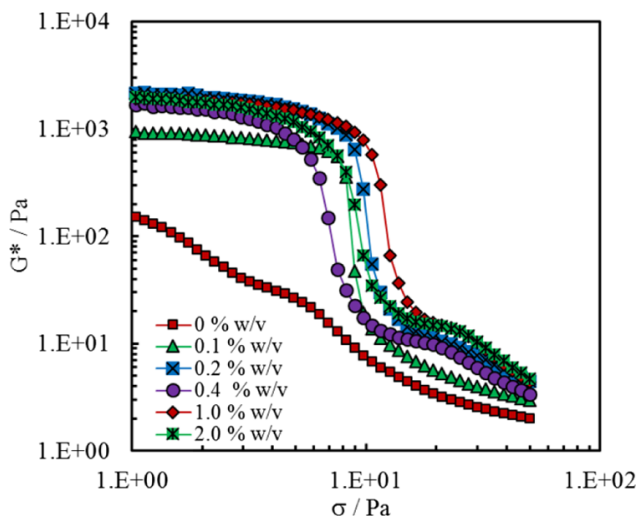

Figure 4. Complex modulus $\left(G^{*}\right)$ as a function of shear stress $(\sigma)$ for a suspension of $10 \mathrm{w} / \mathrm{w} \%$ Socal 312 particles in silicone oil at different concentrations of the secondary phase of $2 \mathrm{w} / \mathrm{v} \%$ aqueous solution of Methocel A4M at $25{ }^{\circ} \mathrm{C}$.

Figure 5 shows that for a fixed concentration of the secondary phase, the temperature at which the measurement

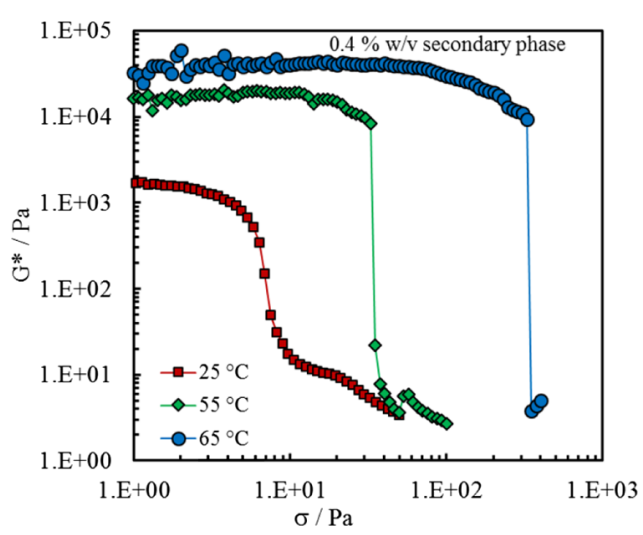

Figure 5. Complex modulus $\left(G^{*}\right)$ as a function of shear stress $(\sigma)$ for a suspension of $10 \mathrm{w} / \mathrm{w} \%$ Socal 312 particles in silicone oil in the presence of $0.4 \mathrm{w} / \mathrm{v} \%$ aqueous solution of Methocel A4M as a secondary liquid phase. The three curves correspond to three different temperatures, 25,55 , and $65^{\circ} \mathrm{C}$.

is made plays a crucial role. At temperatures substantially higher than $50{ }^{\circ} \mathrm{C}$, where the aqueous solution of Methocel A4M is expected to form a strong gel, a greater complex modulus and a greater yield stress were observed than those at low temperatures where the bridging phase is less viscous and flowable.

We measured the cooling-heating curve of $G^{*}$ versus $T$ at a fixed cooling rate (or heating rate) for a Methocel $\mathrm{A} 4 \mathrm{M}$ solution (Figure 6a) and the oil-based capillary suspension with liquid bridges of methyl cellulose solution of the same concentration (Figure 6b). Figure 6 shows the variation in the complex modulus as a function of temperature for $2 \mathrm{w} / \mathrm{v} \%$ aqueous solution of Methocel A4M and also a selected concentration $(1 \mathrm{w} / \mathrm{v} \%)$ of secondary phase, where the secondary phase consists of $2 \mathrm{w} / \mathrm{v} \%$ Methocel A4M in water.

The experiment was carried out in two different settings while heating from 25 to $65{ }^{\circ} \mathrm{C}$ and vice versa. The complex modulus $\left(G^{*}\right)$ of the $2 \mathrm{w} / \mathrm{v} \%$ aqueous solution of Methocel $\mathrm{A} 4 \mathrm{M}$ does change with temperature in the cases of both heating and cooling cycles in a very similar manner, as evident from Figure 6a. Note that $G^{*}$ increases with temperature for the 

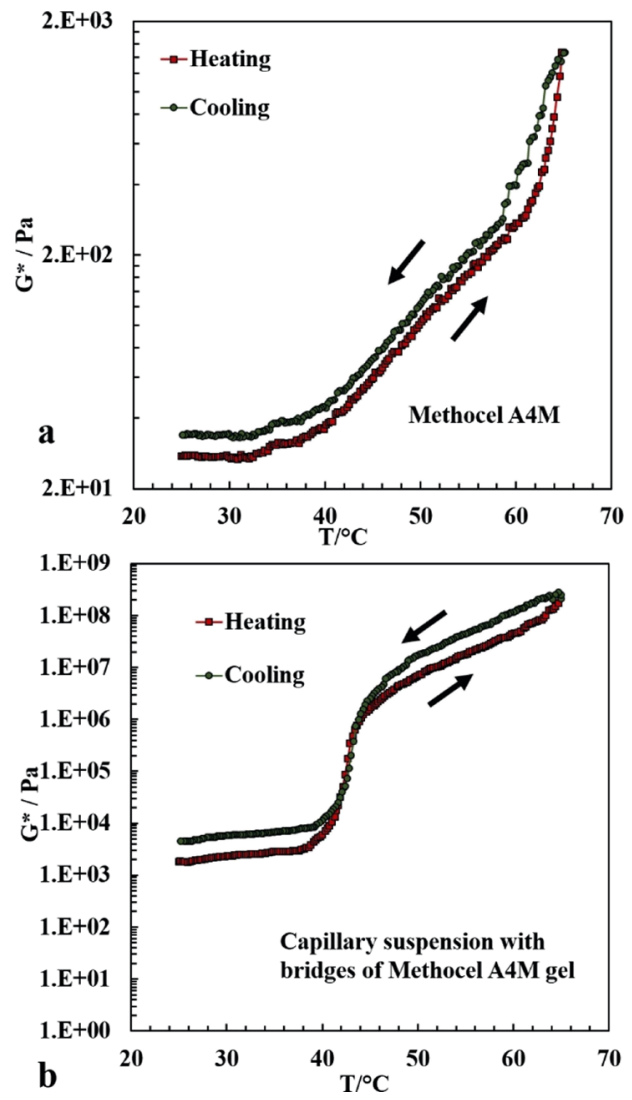

Figure 6. Complex modulus $\left(G^{*}\right)$ vs temperature (T) for (a) $2 \mathrm{w} / \mathrm{v} \%$ aqueous solution of Methocel A4M and (b) $10 \mathrm{w} / \mathrm{w} \%$ Socal 312 particle suspension in silicone oil at $1 \mathrm{w} / \mathrm{v} \%$ aqueous solution of $2 \mathrm{w} /$ $\mathrm{v} \%$ Methocel A4M as a secondary liquid phase. The measurements were done on a rheometer at $1 \mathrm{~Hz}, 5 \mathrm{~Pa}$ applied stress, and a heating/ cooling rate of $1{ }^{\circ} \mathrm{C} \mathrm{min}^{-1}$. The arrows show the directions of the increase and decrease of the temperature during the experimental run.

capillary suspension, which reflects the increase in $G^{*}$ with $T$ for the Methocel A4M solution. There is a small gelling hysteresis for both the methyl cellulose solution and the capillary suspension, which is attributed to the lack of polymer mobility in the gel, which hinders the recovery of the mechanical properties after cooling in comparison to the viscous liquid. ${ }^{28-30}$ It also clearly shows a slope change increase in the complex modulus of the capillary suspension starting at around $35^{\circ} \mathrm{C}$, in line with the results from Figure 1 .

These results demonstrate that the capillary suspension shows a strong response to the external temperature with a steep increase in the complex modulus as it goes over the gelling temperature of the methyl cellulose solution. The magnitude of this stimulus response is remarkable and gives an increase over 3 orders of magnitude of the complex modulus by increasing the methyl cellulose concentration from 0.2 to 1.0 $\mathrm{w} / \mathrm{v} \%$ in the aqueous phase, given that the capillary suspension contains only $2 \mathrm{w} / \mathrm{v} \%$ of aqueous phase. This corresponds to a temperature stimulus effect controlled by the changes in the overall percentage of methyl cellulose ranging from 0.00004 to $0.0002 \mathrm{w} / \mathrm{v} \%$ with respect to the whole capillary suspension system.

In Figure 7, the thermal response is demonstrated visually by tracking the appearance of the capillary suspension sample while varying the temperature. In the LHS column, as the capillary-structured material is cooled from 65 to $25^{\circ} \mathrm{C}$, it loses

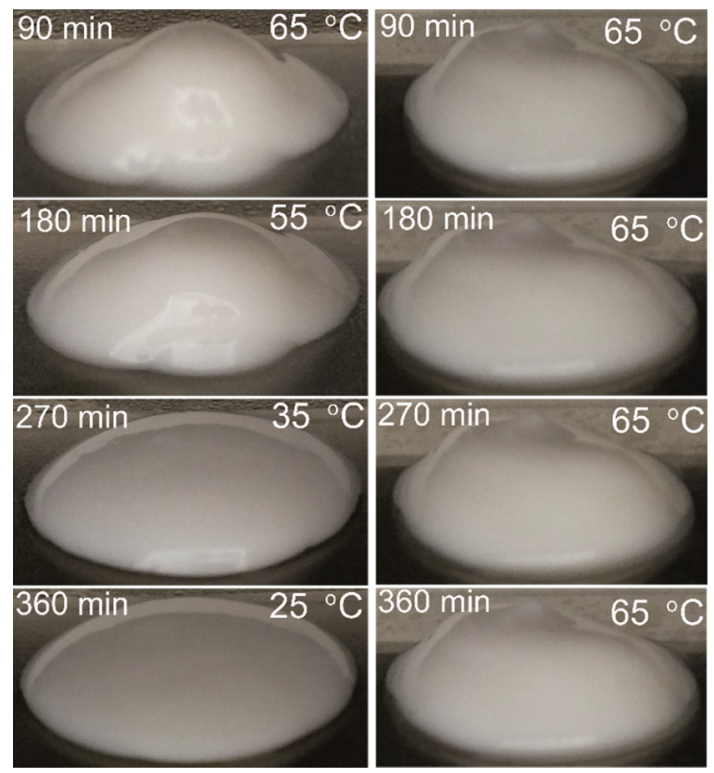

Figure 7. Images of a capillary suspension system of $10 \mathrm{w} / \mathrm{w} \%$ Socal 312 particles in silicone oil containing $1.0 \mathrm{w} / \mathrm{v} \%$ secondary phase of 2 $\mathrm{w} / \mathrm{v} \%$ Methocel A4M aqueous solution. The sample was held for 90 min at each temperature before imaging. The left-hand side (lhs) column shows the sample in the process of cooling; in the right-hand side (rhs) column, the sample was held at $65^{\circ} \mathrm{C}$, from 90 to $360 \mathrm{~min}$.

its ability to keep its shape. It starts as a sculptable material, and after $90 \mathrm{~min}$ at $35{ }^{\circ} \mathrm{C}$, it flows under gravity into a puddle shape. The RHS column of Figure 7 shows the corresponding sample held for the same period of time at $65{ }^{\circ} \mathrm{C}$. This sample does not show such flow and remains as a sculptable material.

The temperature at which the material is able to flow under gravity corresponds to the transition temperature of the Methocel A4M from Figure 1. Here, the primary phase is silicone oil containing $10 \mathrm{w} / \mathrm{w} \%$ Socal 312 particles, and the secondary phase is $2 \mathrm{w} / \mathrm{v} \%$ aqueous solution of Methocel A4M. The results show that there is an increase in $G^{*}$ and yield stress with an increase in the Methocel concentration and hence an increase in the viscosity of the secondary phase.

Figure 8 uses the yield stress and complex modulus at $\sigma=5$ $\mathrm{Pa}$ to summarize a family of complex modulus versus applies stress curves for systems in which the primary phase was silicone oil, the particles are $10 \mathrm{w} / \mathrm{w} \%$ Socal 312 particles, the bridging phase was held constant at $0.4 \mathrm{w} / \mathrm{v} \%$. The concentration of the Methocel A4M in the secondary phase has been varied. These show that increasing the Methocel A4M content increases both the complex modulus and the yield stress. Also, as the temperature is raised, both rheological parameters increase. This supports the hypothesis that the gelation of the Methocel A4M at high temperatures is causing an increase in the viscosity and "strength" of the structure within the capillary suspension.

Rheology of the Capillary Suspension with Hydrogels from SeaPrep Agarose as a Bridging Phase. The complex modulus of suspensions containing $10 \mathrm{w} / \mathrm{w} \%$ Socal 312 dispersed in the primary phase of silicone oil with different concentrations of aqueous solution of SeaPrep agarose (0-2 $\mathrm{w} / \mathrm{v} \%$ ) was measured as a function of the applied stress. It was observed that the increase in the concentration of secondary phase of SeaPrep agarose results in a gradual increase of the complex modulus, as shown in Figure 9. Again, a strong increase in the low stress complex modulus and the yield stress 


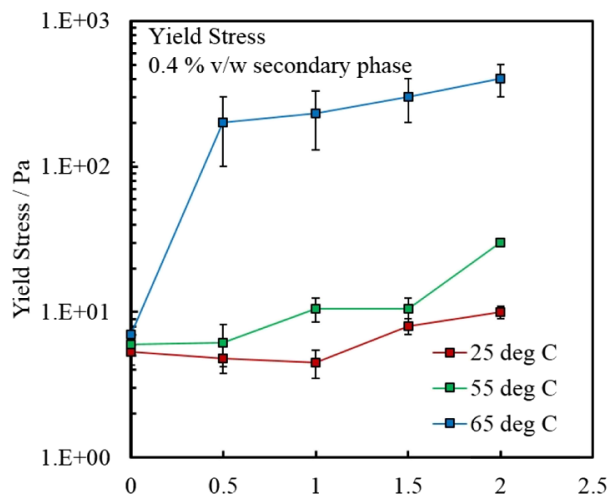

a $[$ Methocel $\mathrm{A} 4 \mathrm{M}]$ in the secondary phase $/ \% \mathrm{w} / \mathrm{w}$

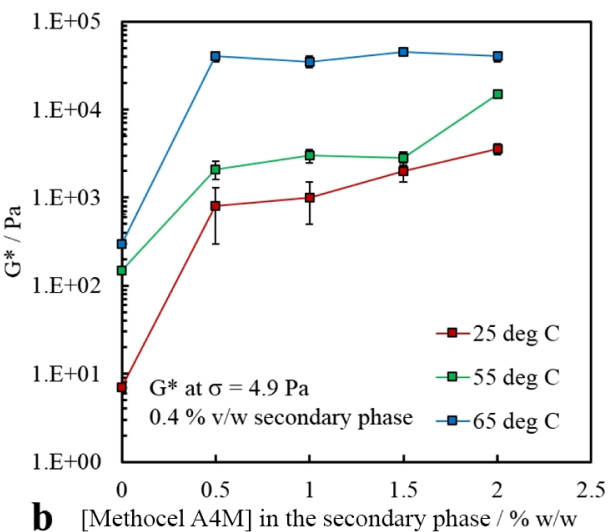

b $[$ Methocel A4M] in the secondary phase $/ \% \mathrm{w} / \mathrm{w}$

Figure 8. Yield stress (a) and complex modulus (b) for a capillary suspension system of $10 \mathrm{w} / \mathrm{w} \%$ Socal 312 particles in silicone oil at 5 Pa applied stress as a function of Methocel A4M concentration in the secondary phase. The three curves correspond to different temperatures, 25, 55, and 65 ${ }^{\circ} \mathrm{C}$.

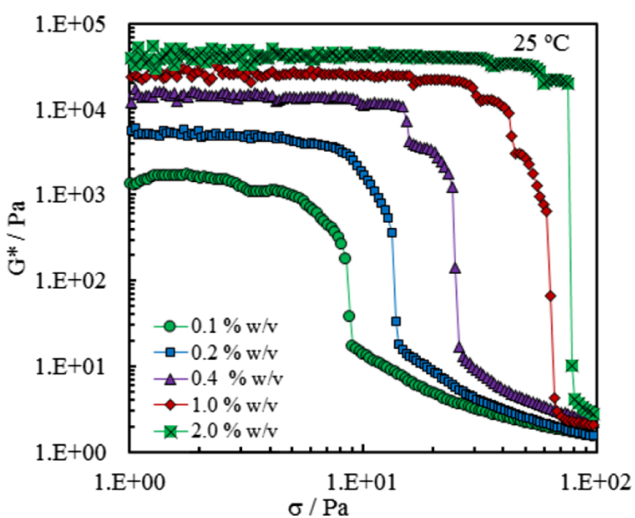

Figure 9. Complex modulus $\left(G^{*}\right)$ as a function of shear stress $(\sigma)$ for a suspension of $10 \mathrm{w} / \mathrm{w} \%$ Socal 312 particles in silicone oil at different concentrations of a secondary phase of $2 \mathrm{w} / \mathrm{v} \%$ aqueous solution of 2 $\mathrm{w} / \mathrm{v} \%$ SeaPrep agarose at $25{ }^{\circ} \mathrm{C}$.

was observed as the amount of bridging phase is increased. For a fixed concentration of the secondary phase, Figure 10 demonstrates that the temperature at which the measurement is made plays a crucial role. At low temperatures, where the SeaPrep agarose in water is expected to form a strong gel, a

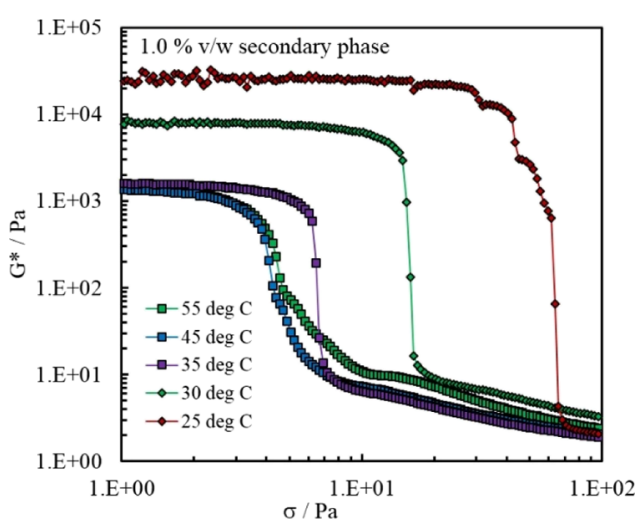

Figure 10. Complex modulus $\left(G^{*}\right)$ as a function of shear stress $(\sigma)$ for a suspension of $10 \mathrm{w} / \mathrm{w} \%$ Socal 312 particles in silicone oil in the presence of $1 \mathrm{w} / \mathrm{v} \%$ aqueous solution of $2 \mathrm{w} / \mathrm{v} \%$ SeaPrep agarose as a secondary liquid phase. The five curves correspond to five different temperatures, $25,30,35,45$, and $55^{\circ} \mathrm{C}$. greater complex modulus and a greater yield stress are observed (Figure 10).

Figure 11 shows the variation in the complex modulus as a function of temperature for $2 \mathrm{w} / \mathrm{v} \%$ aqueous solution of SeaPrep agarose and also a selected concentration $(1 \mathrm{w} / \mathrm{v} \%)$ of the secondary phase, which consists of $2 \mathrm{w} / \mathrm{v} \%$ SeaPrep agarose in water. The experiment was carried out in two
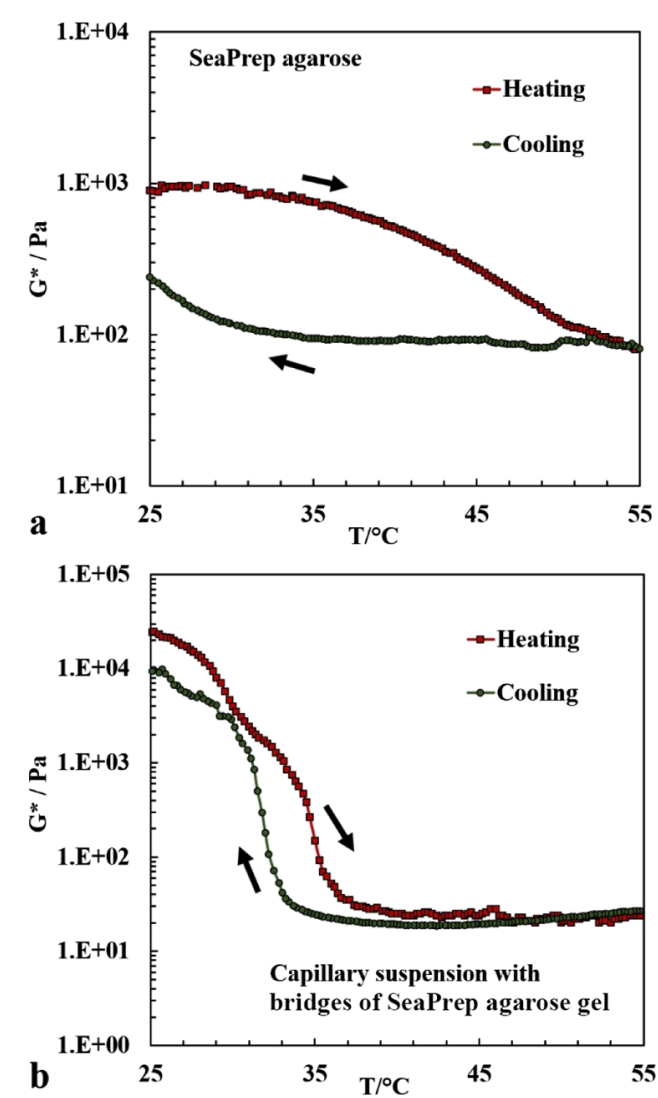

Figure 11. Complex modulus $\left(G^{*}\right)$ vs temperature $(T)$ for (a) an aqueous solution of $2 \mathrm{w} / \mathrm{v} \%$ of SeaPrep agarose and (b) $10 \mathrm{w} / \mathrm{w} \%$ Socal 312 particle suspension in silicone oil with $1 \mathrm{w} / \mathrm{v} \%$ aqueous solution of $2 \mathrm{w} / \mathrm{v} \%$ SeaPrep agarose as a secondary liquid phase. The measurements were done on a rheometer at $1 \mathrm{~Hz}, 5 \mathrm{~Pa}$ applied stress, and a heating rate of $1{ }^{\circ} \mathrm{C} \mathrm{min}-1$. The arrows show the directions of the increase and decrease of the temperature. 
different settings: heating from 25 to $55{ }^{\circ} \mathrm{C}$ and then cooling from 55 to $25{ }^{\circ} \mathrm{C}$. The complex modulus $\left(G^{*}\right)$ of the $2 \mathrm{w} / \mathrm{v} \%$ aqueous solution of SeaPrep agarose does change with temperature in the cases of both heating and cooling cycles in a completely different manner, as evident from Figure 11a. The results show that there is a hysteresis in the gelling and melting properties of SeaPrep agarose. The complex modulus $\left(G^{*}\right)$ is much higher when the agarose gel was melted by heating from $25{ }^{\circ} \mathrm{C}$, whereas it is much lower in case it was cooled from a high temperature to $25{ }^{\circ} \mathrm{C}$, as evident from Figure 11a. This gelling hysteresis behavior has also been observed in many other hydrogels and is believed to be due to the formation of fluid gel during the cooling sweep under shearing. ${ }^{28-30}$

The capillary suspension containing $1 \mathrm{w} / \mathrm{v} \%$ of secondary phase of $2 \mathrm{w} / \mathrm{v} \%$ SeaPrep agarose in water also shows a similar effect in the cases of heating and cooling, as shown in Figure 11 b. It also clearly shows a step change increase in the complex modulus of the capillary suspension starting at around $30{ }^{\circ} \mathrm{C}$, in line with the results from Figure 1. The complex modulus gradually decreases at higher temperatures where the agarose is expected to melt. There is a slight difference between the complex modulus $\left(G^{*}\right)$ values of the capillary suspensions shown in Figure 11 compared to those shown in Figure 10, which is likely due to the formation of different numbers of capillary bridges between the particles in the experiment at a fixed shear stress of $5 \mathrm{~Pa}$ as we bring the system through the temperature cycle of heating and cooling in real time. This type of gelling hysteresis could also be influenced by possible coalescing of liquid bridges during the temperature cycle in addition to the hydrogel-own hysteresis (Figure 11b). It is remarkable that the gelling hysteresis in the hydrogel (Figure 11a) is reflected in the gelling hysteresis of the capillary suspension which actually contains a very small overall amount of hydrogel forming polymer in the liquid bridge-forming phase $(0.02 \%)$. Hence, one can control the rheology of the capillary suspension with an ultrasmall amount of gelling agent in the secondary (bridging) liquid phase.

Capillary suspensions with SeaPrep agarose incorporated into the secondary bridging phase clearly lose their high viscosity and structural rigidity as the temperature of the system is raised to a point where the agarose melts. Taken in conjunction with the opposite behavior for capillary suspensions containing Methocel A4M solution as a secondary phase, where a rise in temperature results in an increase in the viscosity and structural strength of the system. This combination of results demonstrates that the rheological behavior of the bridging phase does indeed play a major role in the overall rheology of the capillary suspension. We also demonstrated that capillary suspensions that are responsive to stimuli such as temperature can be readily manufactured.

\section{CONCLUSIONS}

Capillary suspensions formed of hydrophobized $\mathrm{CaCO}_{3}$ particles (Socal 312) suspended in silicone oil and bridged by small amounts of aqueous hydrogel solutions as a secondary liquid phase have been successfully prepared and exhibited excellent stability with regard to the sedimentation of the particles. We prepared capillary-structured suspensions of Socal 312 particles in silicone oil with aqueous solutions of methyl cellulose (Methocel A4M) as the bridging phase. These showed significant changes in behavior as the temperature of the system is increased above the gelling temperature of the Methocel
A4M solution. Although at low temperatures, they exhibit a low initial complex modulus and yield stress, both of them increase at temperatures above the gelling temperature of the methyl cellulose. These parameters (at any given temperature) increases if the concentration of methyl cellulose in the aqueous phase is increased. They also increase if the overall concentration of the secondary aqueous phase is increased at a fixed concentration of methyl cellulose.

We also fabricated capillary-structured suspensions of Socal 312 particles in silicone oil with a secondary liquid phase of aqueous solutions of SeaPrep agarose. These showed significant changes in rheological behavior as the temperature of the system is increased above the melting temperature of the agarose hydrogel. However, in contrast with the case of methyl cellulose-containing systems, although at low temperatures, the suspension systems with agarose hydrogel bridging phase exhibited a high initial complex modulus and yield stress, these both decrease at temperatures above the melting temperature of the SeaPrep agarose gel. These parameters (at any given temperature) increase if the amount of aqueous phase is increased. It is therefore concluded that capillary-structured materials where the rheology of the bulk material can be significantly altered by the temperature as a stimulus factor and the subsequent rheology of the bridging phase have been demonstrated.

Thermally responsive capillary suspensions could find many potential applications in smart consumer products which rely on a temperature-triggered change in rheology. They can also be used to program the release of actives in pharmaceutical formulations and flavors in foods and many other applications.

\section{ASSOCIATED CONTENT}

\section{(5) Supporting Information}

The Supporting Information is available free of charge on the ACS Publications website at DOI: 10.1021/acsami.7b11358.

Data about the role of the rheometer cone and plate surface coating for simple liquids and capillary suspension with Methocel gel bridges (Figure S1); effect of degassing on the rheology of the capillary suspension (Figure S2) and effect of entrapped air in the system without degassing on the structure of the capillary suspension (SEM images of freeze-dried capillary suspension systems in Figure S3); and discussion of these effects (Figure S4) (PDF)

\section{AUTHOR INFORMATION}

\section{Corresponding Author}

*E-mail: V.N.Paunov@hull.ac.uk. Phone: +44 1482465660. Fax: +44 1482466410 .

\section{ORCID}

Anupam A. K. Das: 0000-0003-1948-8811

Simeon D. Stoyanov: 0000-0002-0610-3110

Vesselin N. Paunov: 0000-0001-6878-1681

\section{Author Contributions}

The manuscript was written through the contributions of all authors. All authors have given approval to the final version of the manuscript.

\section{Funding}

A.D., T.D., and V.P. acknowledge funding of this work from Unilever R\&D Vlaardingen, The Netherlands. 


\section{Notes}

The authors declare no competing financial interest.

\section{ACKNOWLEDGMENTS}

The authors appreciated the technical help from Tony Sinclair at the University of Hull Microscopy Suite with the SEM sample preparation and imaging.

\section{REFERENCES}

(1) Koos, E.; Willenbacher, N. Capillary Forces in Suspension Rheology. Science 2011, 331, 897-900.

(2) Rigden, P. J. Rheology of Suspensions of High Solid Concentration. Nature 1951, 167, 197-198.

(3) Harrison, V. G. W. The science of rheology. Nature 1940, 146, $580-582$.

(4) Stickel, J. J.; Powell, R. L. Fluid mechanics and rheology of dense suspensions. Annu. Rev. Fluid Mech. 2005, 37, 129-149.

(5) Mueller, S.; Llewellin, E. W.; Mader, H. M. The rheology of suspensions of solid particles. Proc. R. Soc. A 2010, 466, 1201.

(6) Brown, E.; Jaeger, H. M. Through thick and thin. Science 2011, 333, 1230-1231.

(7) Dittmann, J.; Koos, E.; Willenbacher, N. Ceramic Capillary Suspensions: Novel Processing Route for Macroporous Ceramic Materials. J. Am. Ceram. Soc. 2013, 96, 391-397.

(8) Hoffmann, S.; Koos, E.; Willenbacher, N. Using capillary bridges to tune stability and flow behavior of food suspensions. Food Hydrocolloids 2014, 40, 44-52.

(9) McCulfor, J.; Himes, P.; Anklam, M. R. The effects of capillary forces on the flow properties of glass particle suspensions in mineral oil. AIChE J. 2011, 57, 2334-2340.

(10) Domenech, T.; Velankar, S. S. On the rheology of pendular gels and morphological developments in paste-like ternary systems based on capillary attraction. Soft Matter 2015, 11, 1500-1516.

(11) Bossler, F.; Koos, E. Structure of particle networks in capillary suspensions with wetting and nonwetting fluids. Langmuir 2016, 32, $1489-1501$

(12) Koos, E.; Johannsmeier, J.; Schwebler, L.; Willenbacher, N. Tuning suspension rheology using capillary forces. Soft Matter 2012, 8, $6620-6628$.

(13) Zhang, J.; Zhao, H.; Li, W.; Xu, M.; Liu, H. Multiple Effects of the Second Fluid on Suspension Viscosity. Sci. Rep. 2015, 5, 16058.

(14) Dittmann, J.; Willenbacher, N. Micro Structural Investigations and Mechanical Properties of Macro Porous Ceramic Materials from Capillary Suspensions. J. Am. Ceram. Soc. 2014, 97, 3787-3792.

(15) Maurath, J.; Dittmann, J.; Schultz, N.; Willenbacher, N. Fabrication of highly porous glass filters using capillary suspension processing. Sep. Purif. Technol. 2015, 149, 470-478.

(16) Bitsch, B.; Dittmann, J.; Schmitt, M.; Scharfer, P.; Schabel, W.; Willenbacher, W. A novel slurry concept for the fabrication of lithiumion battery electrodes with beneficial properties. J. Power Sources 2014, 265, 81-90.

(17) Dittmann, J.; Maurath, J.; Bitsch, B.; Willenbacher, N. Highly Porous Materials with Unique Mechanical Properties from Smart Capillary Suspensions. Adv. Mater. 2016, 28, 1689-1696.

(18) Li, L. Thermal Gelation of Methylcellulose in Water: Scaling and Thermoreversibility. Macromolecules 2002, 35, 5990-5998.

(19) Saha, D.; Bhattacharya, S. Hydrocolloids as thickening and gelling agents in food: a critical review. J. Food Sci. Technol. 2010, 47, 587-597.

(20) Schneider, M.; Koos, E.; Willenbacher, N. Highly conductive, printable pastes from capillary suspensions. Sci. Rep. 2016, 6, 31367.

(21) Wollgarten, S.; Yuce, C.; Koos, E.; Willenbacher, N. Tailoring flow behavior and texture of water based cocoa suspensions. Food Hydrocolloids 2016, 52, 167-174.

(22) Koos, E. Capillary suspensions: Particle networks formed through the capillary force. Curr. Opin. Colloid Interface Sci. 2014, 19, $575-584$.
(23) Koos, E.; Kannowade, W.; Willenbacher, N. Restructuring and aging in a capillary suspension. Rheol. Acta 2014, 53, 947-957.

(24) Koos, E.; Willenbacher, N. Particle configurations and gelation in capillary suspensions. Soft Matter 2012, 8, 3988-3994.

(25) Velankar, S. S. A non-equilibrium state diagram for liquid/fluid/ particle mixtures. Soft Matter 2015, 11, 8393-8403.

(26) Roh, S.; Parekh, D. P.; Bharti, B.; Stoyanov, S. D.; Velev, O. D. 3D Printing by Multiphase Silicone/Water Capillary Inks. Adv. Mater 2017, 29, 1701554

(27) Zhang, Y.; Wang, S.; Zhou, J.; Benz, G.; Tcheimou, S.; Zhao, R.; Behrens, S. H.; Carson-Meredith, J. Capillary Foams: Formation Stages and Effects of System Parameters. Ind. Eng. Chem. Res. 2017, 56, 9533-9540.

(28) Morris, E. R.; Gothard, M. G. E.; Hember, M. W. N.; Mannig, C. E.; Robinson, G. Conformational and rheological transitions of welan, rhamsan and acylated gellan. Carbohydr. Polym. 1996, 30, 165175.

(29) Barrera, C.; Florián-Algarin, V.; Acevedo, A.; Rinaldi, C. Monitoring gelation using magnetic nanoparticles. Soft Matter 2010, 6, 3662-3668.

(30) Nair, K. P.; Breedveld, V.; Weck, M. Complementary hydrogenbonded thermoreversible polymer networks with tunable properties. Macromolecules 2008, 41, 3429-3438.

(31) Dusntan, T. S.; Das, A. K.; Starck, P.; Stoyanov, S. D.; Paunov, V. N. Capillary structured suspensions from in-situ hydrophobized calcium carbonate particles suspended in a polar liquid media. Langmuir 2017, accepted for publication, DOI: 10.1021/ acs.langmuir.7b03589. 